\title{
Utility of Virtual Platform for Conducting Practical Examination for Medical Students During Covid Times: A Prospective Study from Gynaecology Department
}

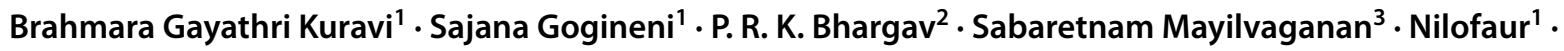 \\ V. Shanthi ${ }^{1}$. Sunitha $\mathrm{Ch}^{1}$
}

Received: 4 June 2021 / Accepted: 11 July 2021 / Published online: 28 August 2021

(c) Federation of Obstetric \& Gynecological Societies of India 2021

\begin{abstract}
Background As the novel coronavirus 2019 (COVID-19) continues its pandemic surge globally along with its social distancing norms, the physical conduction of practical examinations for medical graduates and postgraduates has become difficult. Software-based systems and social media platforms could provide alternatives for ensuring regular medical education and exam-oriented assessments. In this context, we evaluated our own experience with virtual conduction of semester practical exams for medical graduates.

Material and Methods This prospective study was conducted in Gynaecology and Obstetrics department. We employed live streaming educational video conferencing software for virtual consultation between medical students, patients (case presentations), internal and external examiners. The outcomes were evaluated in terms of conduction of various components of practical examination-Viva, case presentations, instruments, slides, specimen examination. Statistical analysis was performed by descriptive statistics through Microsoft Excel sheet.

Results Virtual conduction examination/evaluation was performed on 150 medical students by examiners from a distant location. No problems occurred except few short duration (less than $5 \mathrm{~min}$ ) interruptions due to internet connectivity issues. $125 / 150(83.5 \%)$ of medical students and all examiners ( 2 internal and 2 external) expressed satisfaction with virtual medical evaluation.

Conclusions $83.5 \%$ of medical students and all examiners expressed satisfaction with virtual medical evaluation during this COVID pandemic. Our findings suggest that virtual conduction of practical annual medical exams through virtual video conferencing platform appears to be an optimal alternative during COVID pandemic.
\end{abstract}

Dr Brahmara Gayathri Kuravi, MD, DNB, CUG, MNAMS

is Professor at Department of Gynaecology and Obstetrics, Pinnamaneni Siddartha Institute of Medical Sciences (PSIMS), Chinnavutpalli, Vijayawada, AP, India; Sajana Gogineni is Professor and HOD, Department of Gynaecology and Obstetrics, Pinnamaneni Siddartha Institute of Medical Sciences (PSIMS), Chinnavutpalli, Vijayawada, AP, India; Bhargav PRK is Consultant Endocrine and Metabolic Surgeon, Department of Endocrine and Metabolic Surgery, Endocare Hospital, Vijayawada, AP, India; Sabaretnam Mayilvaganan is Associate Professor, Department of Endocrine and Breast Surgery, SGPGIMS, Lucknow, UP, India; Nilofaur is Assistant Professor, Department of Gynaecology and Obstetrics, Pinnamaneni Siddartha Institute of Medical Sciences (PSIMS), Chinnavutpalli, Vijayawada, AP, India; Shanthi V is Assistant Professor, Department of Gynaecology and Obstetrics, Pinnamaneni Siddartha Institute of Medical Sciences (PSIMS), Chinnavutpalli, Vijayawada, AP, India; Sunitha Ch is Assistant Professor, Department of Gynaecology and Obstetrics, Pinnamaneni Siddartha Institute of Medical Sciences (PSIMS), Chinnavutpalli, Vijayawada, AP, India

Extended author information available on the last page of the article 
Keyword COVID $\cdot$ Medical examination $\cdot$ Practical $\cdot$ Students $\cdot$ Virtual platform

\section{Background}

As the novel coronavirus 2019 (COVID-19) continues its pandemic surge globally, most of healthcare resources are diverted and concentrated on tackling this unprecedented calamity [1-3]. The imposition of lockdown, social distancing, restrictions on travel, limited healthcare resources, personnel and risk of exposure to COVID-19 have restricted physical contacts and meetings. This also resulted in suspension of direct medical education and conduction of graduate practical examinations $[1,4,5]$. Software-based systems such as virtual video conferencing, medical software applications and social media platforms have provided alternative platforms for ensuring regular healthcare and access to clinician with patients $[1,6,7]$. In this context, we explored the utility of virtual platform in our experience, for conducting the semester practical exams for medical graduates.

\section{Material and Methods}

This prospective study with virtual evaluation (VE) was conducted in a tertiary care Gynaecology and Obstetrics department in the month of April 2021. We evaluated the satisfaction quotient of patients based on an ordinal scale of three preferences-Unsatisfactory (Us), Not sure (Ns), Fully satisfactory (S). The option of Unsatisfactory meant that the student preferred only direct evaluation after this COVID pandemic averts and was not satisfied with virtual evaluation. Option Not sure meant that they were neither unsatisfied nor satisfied and not sure about their comparative efficiency. Option Satisfactory meant that the student was fully satisfied with the VE methodology. The response of each student on their preferred mode of evaluation was recorded after each virtual session. We utilized the GoTo meeting appbased group video conferencing mode for VE between three individuals medical student, internal examiner and external examiner. All the VE sessions were conducted through computer (desktop/laptop) at both examiner and student ends. Computers with access to a internet either through regular data plan or $\geq 3 \mathrm{G}$ network or router or WiFi network with a minimum download speed of $100 \mathrm{Kbps}$ (kilobytes per second) were employed for VE. VE consisted two phases. In the first phase, the students presented their long and short case presentations virtually and they were evaluated with viva voce. Subsequently, the knowledge of students was evaluated with regards to pathological specimen, slides and surgical instruments in second phase. The volunteers/technical staff displayed the material at student end and external examiners asked the student to identify them and related information. Based on this evaluation, the score sheets for each student were filled by examiners based on individual performance. Finally, each student was asked to express their satisfaction on ordinal scale. All the data were analysed by the principal investigator in a blinded manner. The study complied with the international ethical norms of the Helsinki DeclarationEthical Principles for Medical Research Involving Human Subjects, 2013 [8]. Details were entered and analysed on a Microsoft Excel sheet.

Social media was defined as websites and applications that enable users to create and share photos/videos and video conference on social networking.

\section{Results}

Virtual conduction examination/evaluation was performed with 150 medical students by examiners from a distant location. No problems occurred except few short duration (less than $5 \mathrm{~min}$ ) interruptions due to internet connectivity issues. $125 / 150(83.5 \%)$ of medical students and all examiners (2 internal and 2 external) expressed satisfaction with virtual medical evaluation. The preference of VE based on satisfaction quotient (Us:Ns:S) was 125:8:17, respectively. The representative illustration is shown in Fig. 1. The students in Us category were unsatisfied with both phases of VE. The students of Ns category were either satisfied with phase I or II, but not with both phases.

\section{Discussion}

As the worldwide pandemic spread of novel coronavirus disease 2019 (COVID-19) continues with its multiple subsequent pandemic waves, most of healthcare resources are getting diverted and concentrated on subjugating this catastrophe by preventive vaccination and triaged treatment [1-3]. COVID-19 also has disrupted the world economy, healthcare budget, travel, access to teaching hospitals, priorities of hospital staff/faculty, increased emphasis on COVID care and home isolation [9-11]. As a collateral damage of these above factors, COVID-19 pandemic has also resulted in handicap of medical education and examination/evaluation of students. Even, the University students are under immense psychological stress due to COVID-19 pandemic $[12,13]$. Though telemedicine facility and online classes compensated for continuous medical education and theory examinations, conduction of practical examinations has become very difficult [14-16]. Conduction of practical 


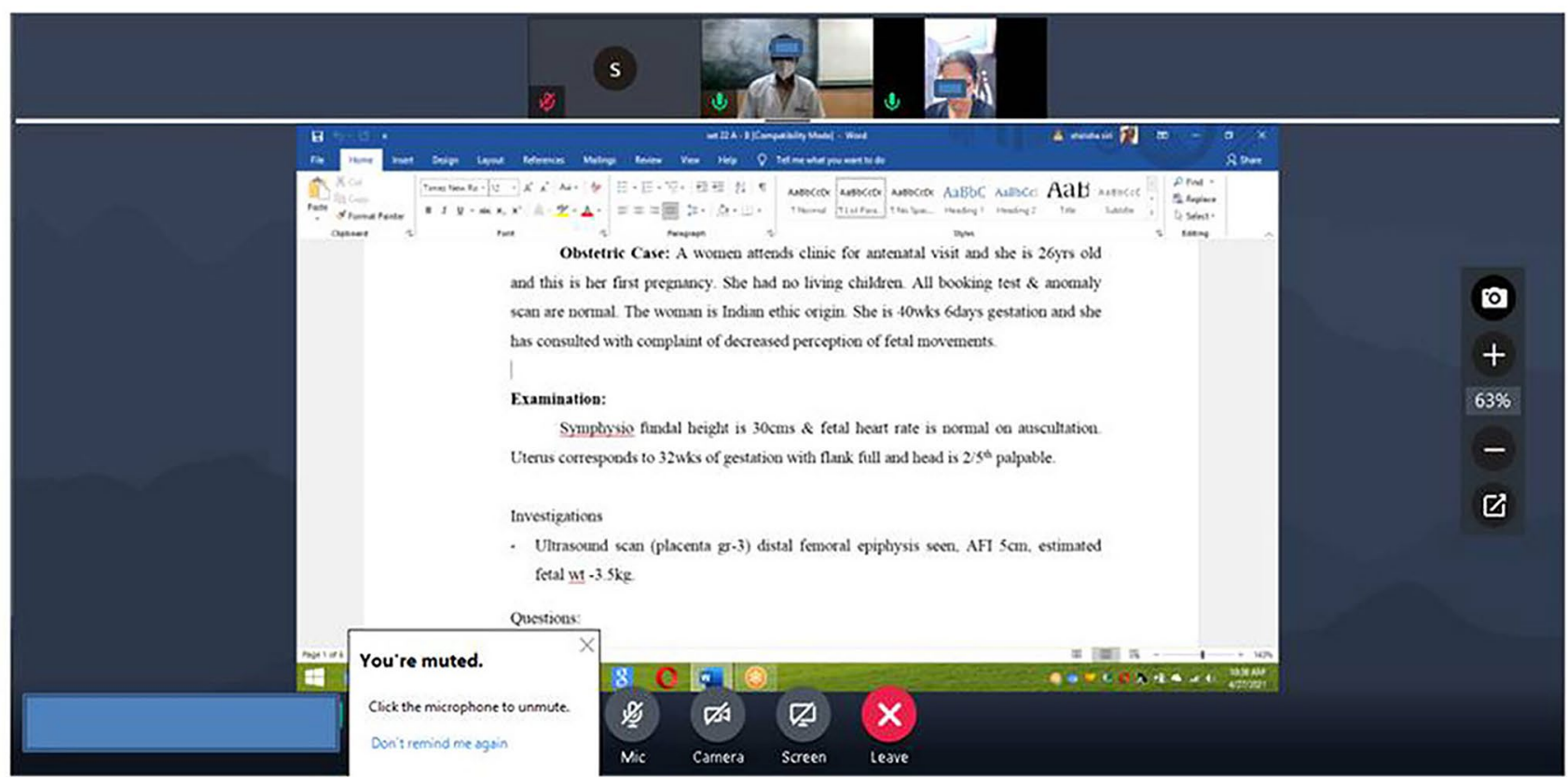

Fig. 1 Phase I VE—-showing student and examiner interaction discussing case presentation

examinations is more difficult than theory part, because the former requires additional needs (with its attendant COVID risk) such as patients (for case presentations), technical staff, display of instruments/pathological specimen and need for interaction between examiners and students. Moreover, there are many impediments such as imposition of lockdown; social distancing; restrictions on travel; limited healthcare resources; limited personnel; and limited personal protection equipment such as masks, sanitizers, gloves and increasing risk of exposure to COVID-19 [1, 9-11].

Software-based systems such as medical software applications and social media platforms could provide alternative platforms for ensuring continuous medical education including evaluation of medical students $[7,14,15]$. As shown in this study, we employed a professional video conferencing software on a desktop/laptop. Elaborate telemedicine setup and equipment were not required for effective VE. Simultaneous involvement of student, examiners (internal and external) and technical assistants during virtual video conferencing ensured no communication gaps, student satisfaction and reduced risk of COVID transmission (Figs. 2, 3).

In our study, VE was satisfactory for all examiners, technical assistants and $83.5 \%$ of medical students. We observed more preference for VE amongst all majority of students/ examiners, primarily because it reduced most of risk factors for COVID spread.

Though the only drawback encountered during VE was, few interruptions due to varying internet speeds and data transfer, the VE sessions were manageable. All these $\mathrm{WiFi}$ interruptions were due to technical reasons such as location of patient, ambient climatic conditions, longer distance from the tower of internet service provider, electricity
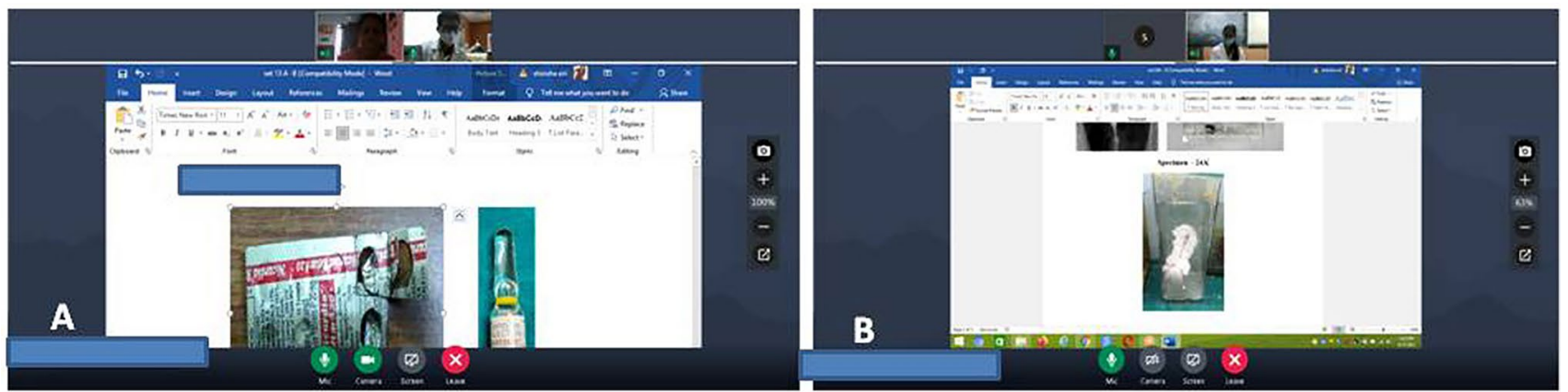

Fig. 2 Phase II VE—-showing student and examiner interaction with latter evaluating former's knowledge on A instruments; $\mathbf{B}$ specimen 
Fig. 3 Bar diagram showing frequency distribution of medical students based on their satisfaction with VE

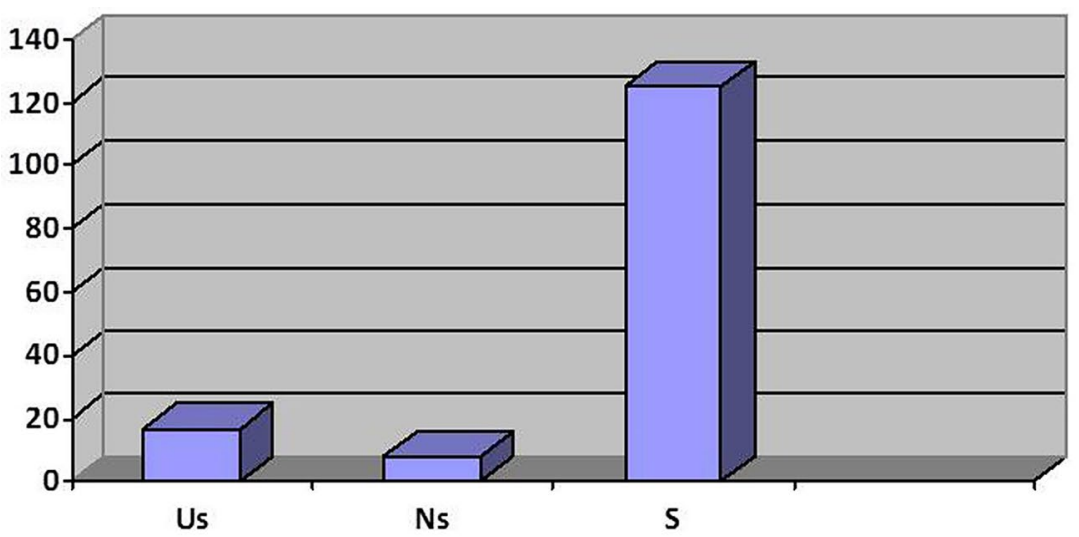

interruptions of internet modems, varying WiFi speeds during VE. Inspite of these minor limitations, VE was a far better option than tedious mobilization, excessive utilisation of human/healthcare/patient/instrumentation/equipment resources and need for human contact/travel required for direct physical evaluation. The only absolute limitation of this VE is lack of computer and/or access to internet. But, we have not encountered this impediment, probably because of the widespread availability of computers and internet with good speed, at affordable prices in India. Another potential problem with this application is possible breach of privacy and hacking of content, which was nullified by the use of inbuilt end-to-end encryption for the users with inaccessible passwords available within software, for each session of VE.

Very few Indian studies addressed the role of virtual conduction of practical examinations of medical students during COVID times [17-19]. Most of the reports were editorials and short reviews. The present study represents a one of its kind original research from India, with specific emphasis on the satisfaction of students with VE. VE ensured optimal utilization of healthcare resources, economy of travel time/ expenses of examiners and reduction in risk of COVID-19 spread apart from avoiding delay of semester exams and ensuring uninterrupted medical education. Our study also highlights the adage "Necessity is the mother of invention", by showing the utility of VE not only during COVID-19 pandemic, but also in post-COVID times in view of its obvious benefits.

\section{Conclusions}

1. More than $83.5 \%$ of medical students and $100 \%$ of examiners/technical assistants preferred virtual evaluation rather than delay in conduction of exams during this COVID pandemic.

2. Our findings suggest that virtual evaluation through social media platforms was capable of ensuring optimal alternative for conduction of practical exams for medical students.

3. Virtual evaluation also ensures uninterrupted medical education and promotion across semesters, for which conduction of medical exams for students is mandatory due to social restrictions imposed during COVID-19 pandemic.

4. Further, the option of VE provides a viable alternative even during post-COVID era.

\section{Declarations}

Conflict of interest The authors declare no conflict of interest. This work has no funding sources, and no financial interests or sponsors involved with this work. It is an independent work.

Human and Animals Rights All procedures performed in studies involving human participants were in accordance with the ethical standards of the institutional and/or national research committee and with the 1964 Helsinki Declaration and its later amendments or comparable ethical standards. There are no animals involved in this study.

Informed Consent Written informed consent was obtained from all the participants in this study.

\section{References}

1. Stawicki SP, Jeanmonod R, Miller AC, et al. The 2019-2020 novel coronavirus (Severe Acute Respiratory Syndrome Coronavirus 2) pandemic: a joint American College of Academic International Medicine-World Academic Council of emergency medicine multidisciplinary COVID-19 working group consensus paper. J Glob Infect Dis. 2020;12:47-93.

2. Yan Y, Shin WI, Pang YX, et al. The first 75 days of novel coronavirus (SARS-CoV-2) outbreak: recent advances, prevention, and treatment. Int J Environ Res Public Health. 2020;17:2323.

3. Cho RHW, Yeung ZWC, Ho OYM, et al. Pearls of experience for safe and efficient hospital practices in otorhinolaryngology-head and neck surgery in Hong Kong during the 2019 novel coronavirus 
disease (COVID-19) pandemic. J Otolaryngol Head Neck Surg. 2020;49:30.

4. Marasco G, Maria Nardone O, Maida M, et al. Impact of COVID19 outbreak on clinical practice and training of young gastroenterologists: a European survey, Italian Association of Young Gastroenterologist and Endoscopist (AGGEI). Dig Liver Dis. 2020;52(12):1396-402.

5. Alsoufi A, Alsuyihili A, Msherghi A, et al. Impact of the COVID19 pandemic on medical education: Medical students' knowledge, attitudes, and practices regarding electronic learning. PLoS ONE. 2020;15(11):e0242905.

6. Woolf SH, Chapman DA, Sabo RT, et al. Excess deaths from COVID-19 and other causes, March-April 2020. JAMA. 2020;324:510-3.

7. Shekhar S, Wurth R, Kamilaris CDC, et al. Endocrine conditions and COVID-19. Horm Metab Res. 2020;52:471-84.

8. World Medical Association. World Medical Association Declaration of Helsinki: ethical principles for medical research involving human subjects. JAMA. 2013;310:2191-4.

9. Park SH. Personal protective equipment for healthcare workers during the COVID-19 pandemic. Infect Chemother. 2020;52:165-82.

10. Goel S, Hawi S, Goel G, et al. Resilient and agile engineering solutions to address societal challenges such as coronavirus pandemic. Mater Today Chem. 2020;17:100300.

11. Panchangam RB, Kota SK, Mayilvaganan S. Letter to the Editor: endocrine and diabetes clinical practice during national lockdown and post lockdown period. Diabetes Metab Syndr. 2020;14:479.

12. Browning MHEM, Larson LR, Sharaievska I, et al. Psychological impacts from COVID-19 among university students: risk factors across seven states in the United States. PLoS ONE. 2021;16(1):e0245327.

13. Son C, Hegde S, Smith A, et al. Effects of COVID-19 on College Students' Mental Health in the United States: interview survey study. J Med Internet Res. 2020;22(9):e21279.

14. Sharma D, Bhaskar S. Addressing Covid-19 burden on medical education and training: the role of telemedicine and tele-education during and beyond pandemic. Front Public Health. 2020;8: 589669. https://doi.org/10.3389/fpubh.2020.589669.

15. Megaloikonomos PD, Thaler M, Igoumenou VG, et al. Impact of the COVID-19 pandemic on orthopaedic and trauma surgery training in Europe. Int Orthop. 2020;44(9):1611-9.

16. Chasset F, Barral M, Steichen O, et al. Immediate consequences and solutions used to maintain medical education during the
COVID-19 pandemic for residents and medical students: a restricted review. Postgrad Med J. 2021. https://doi.org/10.1136/ postgradmedj-2021-139755.

17. Sadeesh T, Prabavathy G, Ganapathy A. Evaluation of undergraduate medical students' preference to human anatomy practical assessment methodology: a comparison between online and traditional methods. Surg Radiol Anat. 2021;43(4):531-5.

18. Pettit M, Shukla S, Zhang J, et al. Virtual exams: has COVID-19 provided the impetus to change assessment methods in medicine? Bone Jt Open. 2021;2(2):111-8.

19. Rajan R, Radhakrishnan DM, Srivastava AK, et al. Conduct of Virtual Neurology DM Final Examination during COVID-19 Pandemic. Ann Indian Acad Neurol. 2020;23(4):429-32.

Publisher's Note Springer Nature remains neutral with regard to jurisdictional claims in published maps and institutional affiliations.

\section{About the Author}

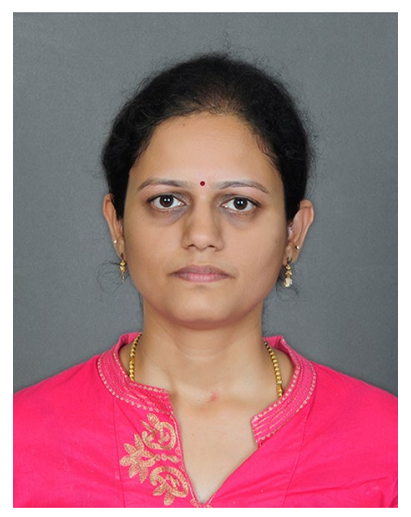

Dr. Brahmara Gayathri Kuravi is currently working as Professor in the department of Gynaecology and Obstetrics at PSIMS, Chinnavutpalli, Vijayawada, AP state, India. She has decent academic experience (15 plus research publications, Thesis works, Guiding Postgraduates), clinical and Operative experience. She has special interest in Laparoscopy, Urogynaecology and Infertility. Performed wide variety of surgeries such as TLH, LAVH, NDVH, Wertheim's operation, VVF repair, Hysteroscopy, Lap myomectomy, Lap ovarian cyst excision, Lap ectopics etc., Presented several papers in state level and national CMEs and conferences.

\section{Authors and Affiliations}

\section{Brahmara Gayathri Kuravi ${ }^{1}$ - Sajana Gogineni ${ }^{1}$ P. R. K. Bhargav ${ }^{2} \cdot$ Sabaretnam Mayilvaganan $^{3} \cdot$ Nilofaur $^{1}$. V. Shanthi ${ }^{1}$. Sunitha $\mathrm{Ch}^{1}$}

Brahmara Gayathri Kuravi

dr.gayathri.bhargav@gmail.com

1 Department of Gynaecology and Obstetrics, Pinnamaneni Siddartha Institute of Medical Sciences (PSIMS), Chinnavutpalli, Vijayawada, AP, India
2 Department of Endocrine and Metabolic Surgery, Endocare Hospital, Vijayawada, AP, India

3 Department of Endocrine and Breast Surgery, SGPGIMS, Lucknow, UP, India 